Research Article

\title{
Microstructure and Properties of a 2.25Cr1Mo0.25V Heat-Resistant Steel Produced by Wire Arc Additive Manufacturing
}

\author{
Chun Guo $\mathbb{D}^{D}$, Suhang Liu, Ruizhang Hu, Chunhui Liu $(\mathbb{D}$, and Feng Chen \\ College of Mechanical Engineering, Anhui Science and Technology University, Bengbu 233000, China \\ Correspondence should be addressed to Chun Guo; guochun@ahstu.edu.cn
}

Received 17 December 2019; Revised 7 February 2020; Accepted 12 March 2020; Published 7 April 2020

Academic Editor: Raul Arenal

Copyright (c) 2020 Chun Guo et al. This is an open access article distributed under the Creative Commons Attribution License, which permits unrestricted use, distribution, and reproduction in any medium, provided the original work is properly cited.

\begin{abstract}
Wire arc additive manufacturing (WAAM) technology was used to produce samples of a 2.25Cr1Mo0.25V heat-resistant steel. The phase composition, microstructure, and crystal structure of the investigated material in the as-cladded state and postcladding heat-treated $\left(705^{\circ} \mathrm{C} \times 1 \mathrm{~h}\right)$ state were analysed by optical emission spectrometry (OES), optical microscopy, scanning electron microscopy (SEM), and transmission electron microscopy (TEM). The properties of the investigated material in the as-cladded state and postcladding heat-treated $\left(705^{\circ} \mathrm{C} \times 1 \mathrm{~h}\right)$ state were determined by a microhardness tester, mechanical properties tester, and Charpy impact tester. Through a study of the microstructure and properties, it is found that the investigated material produced by WAAM exhibits good forming quality and excellent metallurgical bonding properties, and no obvious defects are found. The microstructure consists mainly of $\mathrm{Bg}$ (granular bainite) and troostite precipitated at the grain boundaries. The results from high-resolution transmission electron microscopy observations show that the crystal structures of the $2.25 \mathrm{Cr} 1 \mathrm{Mo} 0.25 \mathrm{~V}$ heat-resistant steel samples produced by WAAM in the as-cladded condition have many defects, such as dislocations and martensite-austenite (M-A) constituents, and their grain edges are sharp. There is a dramatic decrease in the dislocations in the $2.25 \mathrm{Cr} 1 \mathrm{Mo} 0.25 \mathrm{~V}$ heat-resistant steel samples produced by the WAAM condition after the postcladding heat treatment $\left(705^{\circ} \mathrm{C} \times 1 \mathrm{~h}\right)$, and the grains become smooth. The distribution of the microhardness in the longitudinal and transverse cross sections of the samples is very uniform. The average longitudinal and transverse microhardness of the samples in the as-cladded state is $310 \mathrm{HV}_{0.5}$ and $324 \mathrm{HV}_{0.5}$, respectively. The average longitudinal and transverse microhardness of the samples after postcladding heat treatment is $227 \mathrm{HV}_{0.5}$ and $229 \mathrm{HV}_{0.5}$, respectively. The yield strength of the samples without a postcladding heat treatment is $743 \mathrm{MPa}$, the tensile strength is $951 \mathrm{MPa}$, the elongation is $10 \%$, and the Charpy impact value at $-20^{\circ} \mathrm{C}$ is $15 \mathrm{~J}$. After the postcladding heat treatment, the yield strength, tensile strength, elongation, and Charpy impact value of the samples are $611 \mathrm{MPa}$, $704 \mathrm{MPa}, 14.5 \%$, and $70 \mathrm{~J}$, respectively.
\end{abstract}

\section{Introduction}

Additive manufacturing (AM) is also called three-dimensional printing (3D printing) and differs from traditional material reduction (machining) processing technologies [1-4]. Additive manufacturing uses an established threedimensional data model of the parts. According to the discrete-collecting principle, different heat sources (such as a laser beam, an ion beam, an electron beam, an arc, and ultraviolet light) are used to treat the raw materials (such as powders, wires, and liquids) in layer-by-layer fabrication method used to produce parts. Additive manufacturing technology has prominent characteristics compared with those for traditional processing technologies. These characteristics include a short manufacturing cycle (shortening the time from the design to a test sample to production), a possible reduction in production costs, high material utilization (some raw materials can be reused), highly integrated design and manufacturing (personalized design), and optimization of the structure of the parts and components during the design phase. It is especially suitable for components with complex structures (such as hollow structures) 
or high-value raw materials. AM has broad application prospects in the aerospace industry, automobile industry, biomedical treatment, education, mould manufacturing, and other fields and is known as one of the key technologies to promote the "third industrial revolution" [5-9].

Additive manufacturing technology can be divided into metal additive manufacturing and nonmetal additive manufacturing according to different materials. According to the types of heat sources, metal additive manufacturing mainly includes laser additive manufacturing, electron beam additive manufacturing, plasma additive manufacturing, and wire arc additive manufacturing (WAAM) [10-15]. Compared with other additive manufacturing technologies, WAAM technology has a high production efficiency and the ability to fabricate large parts. The disadvantage of WAAM technology is that its manufacturing accuracy is not as good as that of laser additive manufacturing and electron beam additive manufacturing [16-20]. In recent years, WAAM technology has attracted considerable attention in the aerospace industry, mechanical equipment industry, and other fields [21-25].

However, at present, there are relatively few reports regarding additive manufacturing of heat-resistant steel parts. Y. Ali et al. presented investigations on the additive manufacturing of hot work steel (X37CrMoV 5-1) with the cold metal transfer (CMT) process and analysed the influence of the arc energy and thermal field on the resulting mechanical properties and microstructure of the material [26]. The microstructure and properties of a novel heat-resistant $\mathrm{Al}-3 \mathrm{Ce}-7 \mathrm{Cu}$ alloy produced by additive manufacturing were investigated by D. R. Manca et al. [27]. Muh-Rong Wang et al. produced metal powders of heat-resistant steel with a fine microstructure for additive manufacturing [28]. However, they did not study the properties of samples made of heatresistant steel powders by additive manufacturing. Therefore, in this paper, WAAM technology is studied by using $2.25 \mathrm{Cr} 1 \mathrm{Mo} 0.25 \mathrm{~V}$ heat-resistant steel welding wire. $2.25 \mathrm{Cr} 1 \mathrm{Mo} 0.25 \mathrm{~V}$ steel is a newly developed heat-resistant steel. Compared with 2.25Cr1Mo heat-resistant steel, $2.25 \mathrm{Cr} 1 \mathrm{Mo} 0.25 \mathrm{~V}$ heat-resistant steel can be used at higher temperatures and its hydrogen resistance is better. It has begun to be widely used in the manufacture of hydrogenation reaction devices [29-31]. It is expected that this research can provide theoretical and data support for the popularization and application of additive manufacturing technology.

\section{Experimental Procedures}

The experimental wire matched the composition of $2.25 \mathrm{Cr} 1 \mathrm{Mo} 0.25 \mathrm{~V}$ heat-resistant steel. The wire grade was ER90S-G with a diameter of $1.2 \mathrm{~mm}$, and it was produced by the Luoyang Ship Material Research Institute. The chemical composition of the welding wire is shown in Table 1. A TPS4000 cold metal transfer (CMT) advanced power supply, an IRB 1410 KUKA six-axis robot, and an Iungo PNT robot with WAAM software comprised the WAAM equipment. The experimental substrate was ASTM A283M Gr. C steel with dimensions of $300 \mathrm{~mm} \times 100 \mathrm{~mm} \times 10 \mathrm{~mm}$. Before the experiment, the surface of the substrate was polished with a hand grinding wheel to remove the rust and oxide coating on the surface of the steel plate. To reduce the deflection of the base steel plate during the additive manufacturing process, a designed work holder was used to fix the base steel plate. In this study, the CMT mode was adopted in the WAAM process. Single-layer single-pass, single-layer multipass, and multilayer multipass experiments were carried out in the early stage of the experiment. Improved processing parameters were selected according to the shape of the cladded pass. To control the forming accuracy of the additive manufacturing sample, a FLUKE F59 infrared thermometer was used to measure the interpass temperature during the additive manufacturing process. The technological parameters selected for this additive manufacturing study are as follows. The current was $82 \mathrm{~A}$, the voltage was $19.9 \mathrm{~V}$, the wire feeding speed was $4.2 \mathrm{~m} \mathrm{~min}^{-1}$, the shielding gas was $99.9 \% \mathrm{Ar}$, the gas flow was $20 \mathrm{~L} \mathrm{~min}^{-1}$, and the interpass temperature was no less than $150^{\circ} \mathrm{C}$. The specific process parameters are shown in Table 2.

The size of the printed sample (thin wall) produced by WAAM was approximately $150 \mathrm{~mm} \times 20 \mathrm{~mm} \times 60 \mathrm{~mm}$. The samples for metallographic analysis (hardness testing and SEM), transmission electron microscopy (TEM), and chemical composition analysis were prepared from the middle position of the sample by a band sawing machine and wire electrical discharge machining (WEDM). The tensile and impact samples were produced parallel and perpendicular to the depositional direction on both sides. The chemical composition analysis experiment was carried out according to ASTM E415-2015 using the QSN750-II OES. Tensile tests were carried out according to the ASTM E8M-2013 a standard. Tensile properties were tested at room temperature by using a $100 \mathrm{kN}$ material testing machine (SINTECH20/G). Displacement control was used in the tensile test. The initial strain rate of the sample was $0.005 \mathrm{~min}^{-1}$. The impact testing of the samples was carried out according to ASTM E23-2016b. The Charpy impact test (ZBC2302-C) was used. The test temperature was $-50^{\circ} \mathrm{C}$. Three samples were tested in each group. After the metallographic and scanning electron microscopy (SEM) specimens were polished, they were etched with a $4 \%$ hydrochloric acid and ethanol solution. A ZEISS Observer Z1m microscope was used to observe the microstructures of the metallographic samples according to ASTM E112-2013 standard. The microstructure of the metallographic samples at high magnification was observed by a Quanta600 scanning electron microscope. A Genesis Apex 2 $\mathrm{X}$-ray energy dispersive spectroscopy (EDS) instrument was attached to the SEM and was used for composition analysis. The TEM samples were cut into $0.5 \mathrm{~mm}$ thin plates from the bulk specimens and ground to approximately 120 microns in thickness. Three wafers were punched and ground to 50 microns. The perforated film samples were obtained by twinjet electropolishing at $-20^{\circ} \mathrm{C}$. The electrolyte was $4 \%$ perchloric acid and ethanol, and the electrolytic voltage was $75 \mathrm{~V}$. Next, the samples were thinned by a Gatan 691 ion beam thinner that used Ar ions for $0.5 \mathrm{~h}$. The crystal structure of the thinned TEM samples was observed by JEM-2100 transmission electron microscope with an accelerating voltage of $200 \mathrm{kV}$. According to the ASTM E384-2017 standard, the Vickers hardness was measured on a VMH-104 microhardness tester. The test force was $500 \mathrm{gf}$, and the dwell time 
TABLE 1: Chemical composition (wt\%) of the $2.25 \mathrm{Cr} 1 \mathrm{Mo} 0.25 \mathrm{~V}$ solid wire.

\begin{tabular}{lcccccccc}
\hline Sample & $\mathrm{C}$ & $\mathrm{Si}$ & $\mathrm{Mn}$ & $\mathrm{Cr}$ & $\mathrm{Mo}$ & $\mathrm{V}$ & $\mathrm{Ni}$ & $\mathrm{Fe}$ \\
\hline $2.25 \mathrm{Cr} 1 \mathrm{Mo} 0.25 \mathrm{~V}$ & 0.098 & 0.135 & 0.398 & 2.37 & 1.00 & 0.289 & 0.017 & Bal. \\
\hline
\end{tabular}

TABLE 2: Wire arc additive manufacturing parameters.

\begin{tabular}{lccccccccc}
\hline Sample & $\begin{array}{c}\text { Current } \\
(\mathrm{A})\end{array}$ & $\begin{array}{c}\text { Voltage } \\
(\mathrm{V})\end{array}$ & $\begin{array}{c}\text { Wire feeding } \\
\text { speed } \\
\left(\mathrm{m} \cdot \mathrm{min}^{-1}\right)\end{array}$ & $\begin{array}{c}\text { Printing } \\
\text { speed } \\
\left(\mathrm{m} \cdot \mathrm{s}^{-1}\right)\end{array}$ & $\begin{array}{c}\text { Contact tip to } \\
\text { work distance } \\
(\mathrm{mm})\end{array}$ & $\begin{array}{c}\text { Shielding gas } \\
\text { flow } \\
\left(\mathrm{L} \cdot \mathrm{min}^{-1}\right)\end{array}$ & $\begin{array}{c}\text { Interpass } \\
\text { temperature } \\
\left({ }^{\circ} \mathrm{C}\right)\end{array}$ & $\begin{array}{c}\text { Overlap } \\
\text { rate }(\%)\end{array}$ & $\begin{array}{c}\text { Heat } \\
\text { treatment } \\
\left({ }^{\circ} \mathrm{C} \times \mathrm{h}\right)\end{array}$ \\
\hline $1 \#$ & 82 & 19.9 & 4.2 & 10 & 15 & 20 & $\geq 150$ & 50 & None \\
$2 \#$ & 82 & 19.9 & 4.2 & 10 & 15 & 20 & 2150 & 50 & $705 \times 1$ \\
\hline
\end{tabular}

was $15 \mathrm{~s}$. During the test, 10 points ( $1 \mathrm{~mm}$ interval per point) were measured from the upper part $(2 \mathrm{~mm})$ to the lower part of the cladded seam.

\section{Results and Analysis}

3.1. Forming Characteristics of the 2.25Cr1Mo0.25V HeatResistant Steel. Figure 1 shows a $2.25 \mathrm{Cr} 1 \mathrm{Mo} 0.25 \mathrm{~V}$ heatresistant steel thin-wall sample printed by WAAM technology. From the sample images, it can be seen that the 2.25Cr1Mo0.25V heat-resistant steel thin wall printed with the CMT power supply is well formed and does not collapse, but there are solidified metal particles produced by cladding spatter during the forming process. In addition, the crosssectional morphology of the metallographic sample is given in Figure 2, and Figure 2(a) shows the as-cladded state for sample \#1, and Figure 2(b) shows the postcladding heattreated $\left(705^{\circ} \mathrm{C} \times 1 \mathrm{~h}\right)$ state for sample \#2. It can be seen that there are a small number of cold insulation and air hole defects in the sample, and the metallurgical bonding between the deposited layers is good, which further illustrates the good formability of the $2.25 \mathrm{Cr} 1 \mathrm{Mo} 0.25 \mathrm{~V}$ heat-resistant steel produced by WAAM.

3.2. Composition and Microstructure Characteristics of 2.25Cr1Mo0.25V Heat-Resistant Steel Produced by WAAM. Table 3 shows the results of the chemical composition analysis of the $2.25 \mathrm{Cr} 1 \mathrm{Mo} 0.25 \mathrm{~V}$ heat-resistant steel samples produced by WAAM. By comparing the chemical composition of the raw wire given in Table 1, it can be seen that the burning loss rates of the main deoxidizing element $\mathrm{Si}$ for the two $2.25 \mathrm{Cr} 1 \mathrm{Mo} 0.25 \mathrm{~V}$ heat-resistant steel samples produced by additive manufacturing are $53.3 \%$ and $52.6 \%$, and the burning loss rates of the deoxidizing element $\mathrm{Mn}$ are $53.3 \%$ and $52.6 \%$. The transition rates are $88.6 \%$ and $89.5 \%$ for the main alloying element $\mathrm{Cr}, 95.9 \%$ and $95.9 \%$ for alloying element Mo, and $80.6 \%$ and $82.0 \%$ for alloying element V. From the chemical composition results, it can be seen that the deoxidized elements in the cladding wire are burned more so than the other elements and the transition rate of alloy elements is high, which indicates that the deoxidized elements are thoroughly deoxidized during the WAAM process, and the deoxidization performance of the furnace hearth is good.

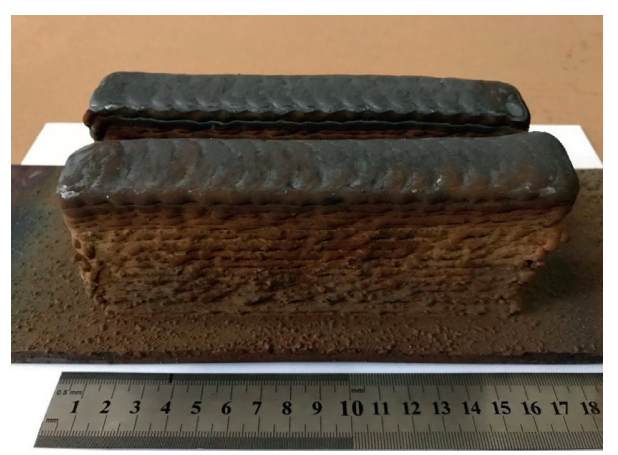

FIGURE 1: Schematic of a $2.25 \mathrm{Cr} 1 \mathrm{Mo} 0.25 \mathrm{~V}$ heat-resistant steel sample produced by WAAM.

Figure 3 shows metallographic images of different locations on the $2.25 \mathrm{Cr} 1 \mathrm{Mo} 0.25 \mathrm{~V}$ heat-resistant steel produced by WAAM. From Figures 3(a) and 3(b), it can be seen that the structure of the columnar crystal zone in the $2.25 \mathrm{Cr} 1 \mathrm{Mo} 0.25 \mathrm{~V}$ heat-resistant steel produced by WAAM is mainly granular bainite. The remelted zone in the $2.25 \mathrm{Cr} 1 \mathrm{Mo} 0.25 \mathrm{~V}$ heat-resistant steel produced by WAAM is composed of granular bainite and troostite that precipitated at the grain boundaries, as shown in Figures 3(c) and 3(d). The microstructure of the heat-affected zone is granular bainite + troostite that precipitated at the grain boundaries, as shown in Figures 3(e) and 3(f). In addition, it can be seen from the high-magnification metallographs that no defects, such as microcracks, can be seen. Figure 4 shows SEM images and energy dispersive spectroscopy of inclusion in the as-cladded samples, and no microcracks can be seen in the high-magnification SEM images. In addition, it can be seen that the morphology of the inclusions in the sample is basically spherical, and the corresponding energy dispersive spectroscopy results show that the inclusions are mainly composed of silicon and manganese oxides.

To further clarify the crystal structure of the 2.25Cr1Mo0.25V heat-resistant steel sample made by WAAM, TEM analysis was conducted. Figure 5 shows a TEM image of the sample. It can be seen from the TEM image in Figure 5(a) that the crystal structure of the sample is an obviously granular bainite structure (M-A constituent exists), and the analysis result of the corresponding selected area electron diffraction (SAED) shows that the matrix is ferrite. Figures 6(a) and 6(b) show a high-magnification 


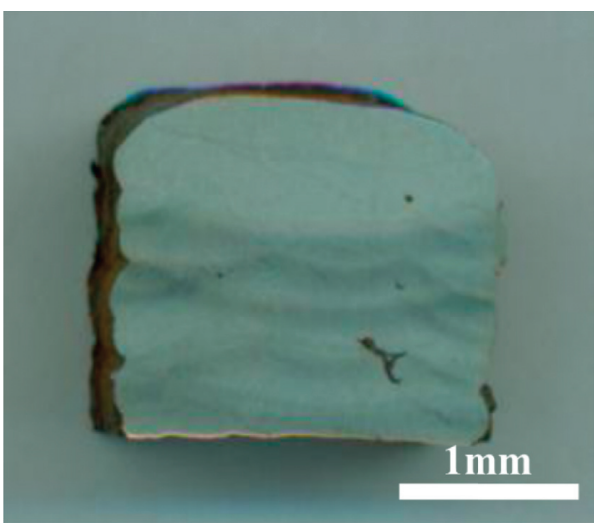

(a)

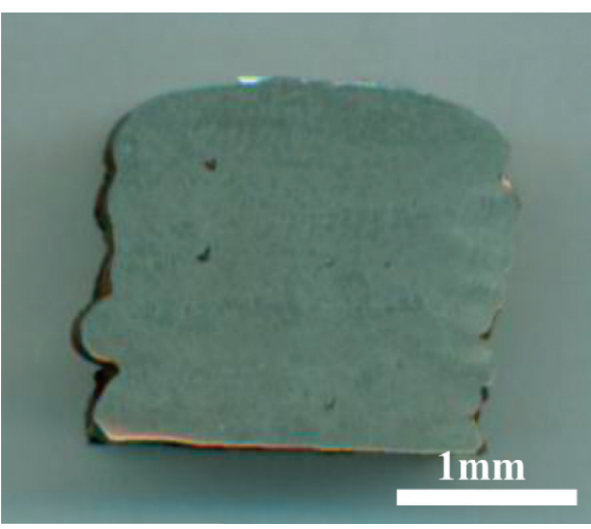

(b)

Figure 2: Cross-sectional morphology of the 2.25Cr1Mo0.25V heat-resistant steel produced by WAAM: (a) the as-cladded state for sample $\# 1$ and (b) the postcladding heat-treated $\left(705^{\circ} \mathrm{C} \times 1 \mathrm{~h}\right)$ state for sample $\# 2$.

TABLE 3: Chemical composition (wt $\%$ ) of the $2.25 \mathrm{Cr} 1 \mathrm{Mo} 0.25 \mathrm{~V}$ sample made by WAAM.

\begin{tabular}{lcccccccc}
\hline Sample & $\mathrm{C}$ & $\mathrm{Si}$ & $\mathrm{Mn}$ & $\mathrm{Cr}$ & $\mathrm{Mo}$ & $\mathrm{V}$ & $\mathrm{Ni}$ & $\mathrm{Fe}$ \\
\hline \#1 (as-cladded) & 0.111 & 0.063 & 0.263 & 2.10 & 0.959 & 0.233 & 0.016 & $\mathrm{Bal}$ \\
\#2 (after heat treatment) & 0.113 & 0.064 & 0.269 & 2.12 & 0.959 & 0.237 & 0.016 & $\mathrm{Bal}$ \\
\hline
\end{tabular}

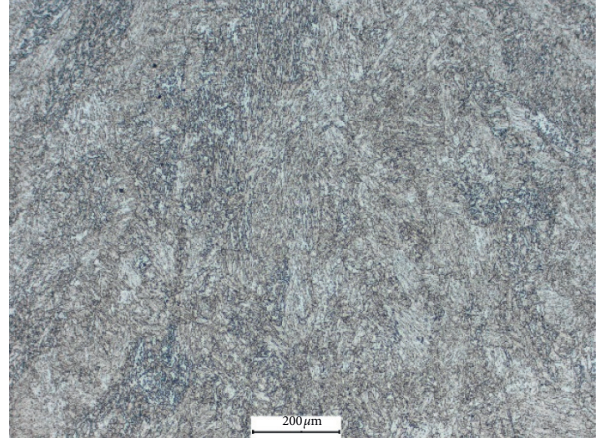

(a)

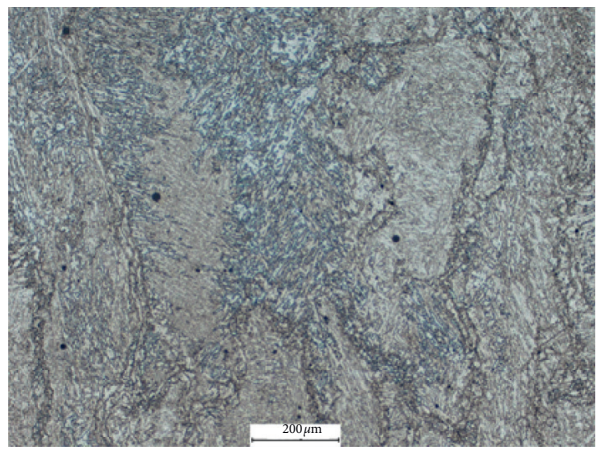

(c)

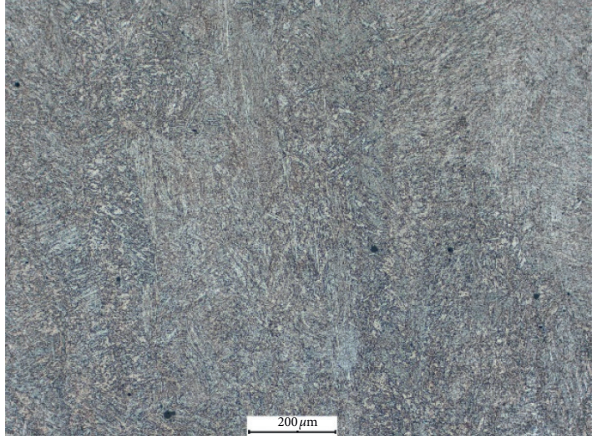

(b)

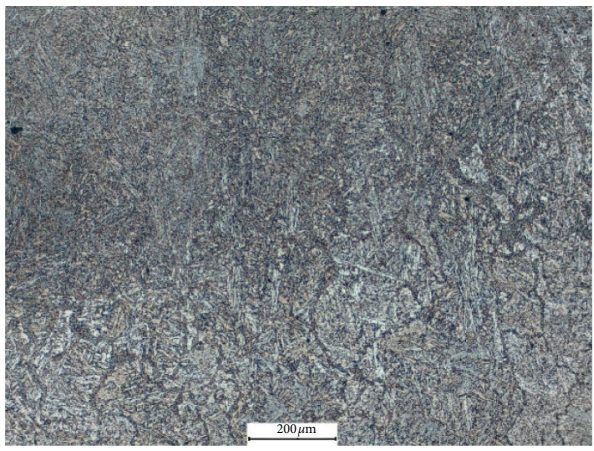

(d)

Figure 3: Continued. 


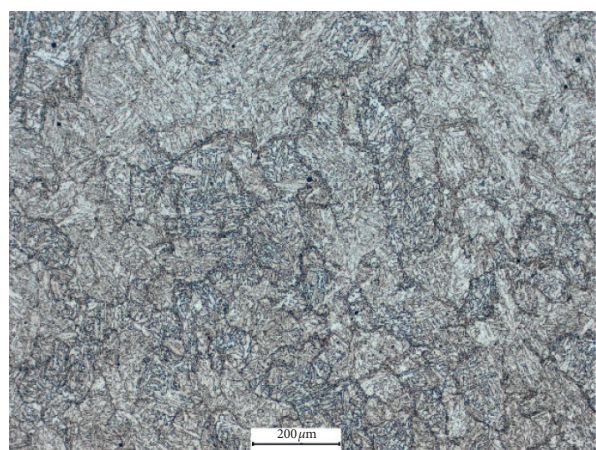

(e)

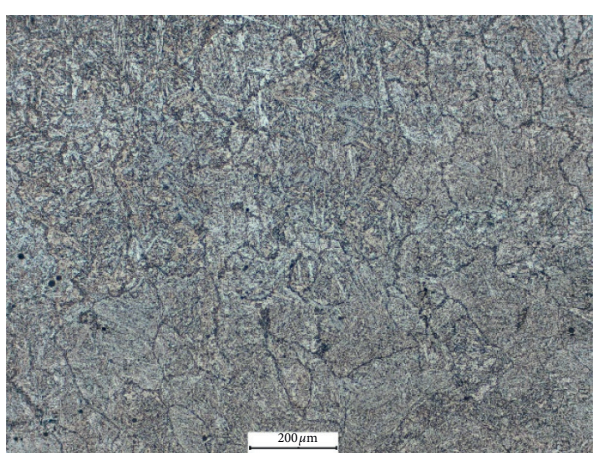

(f)

FIGURE 3: Microstructures of the specimens: (a) columnar crystals in sample \#1, (b) columnar crystals in sample \#2, (c) remelted zone in sample \#1, (d) remelted zone in sample \#2, (e) heat-affected zone in sample \#1, and (f) heat-affected zone in sample \#2.

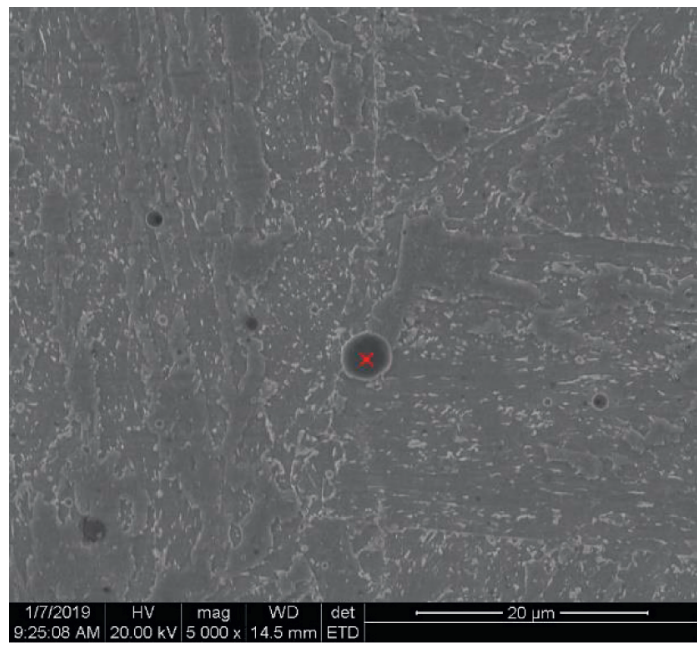

(a)

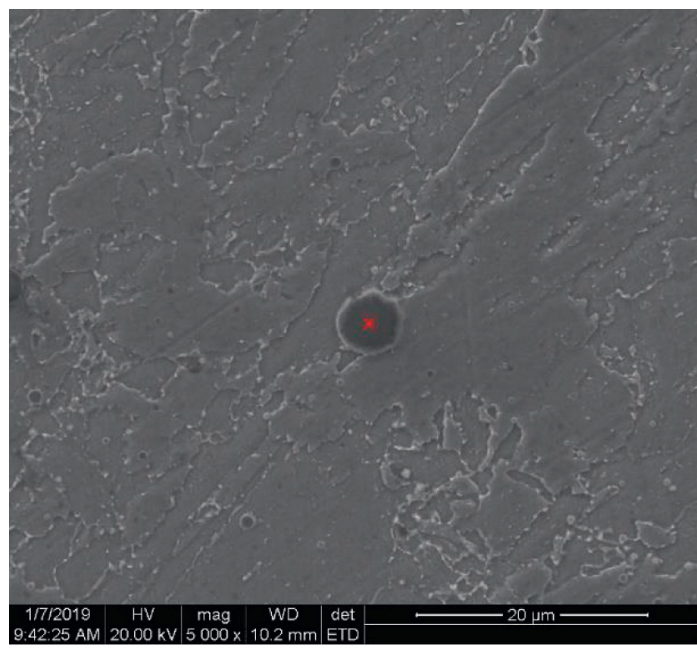

(c)

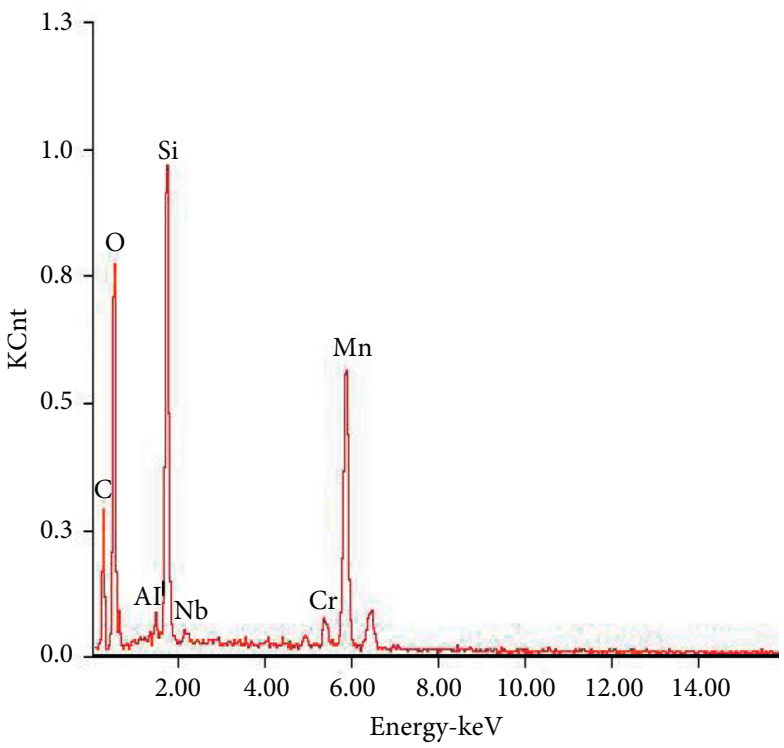

(b)

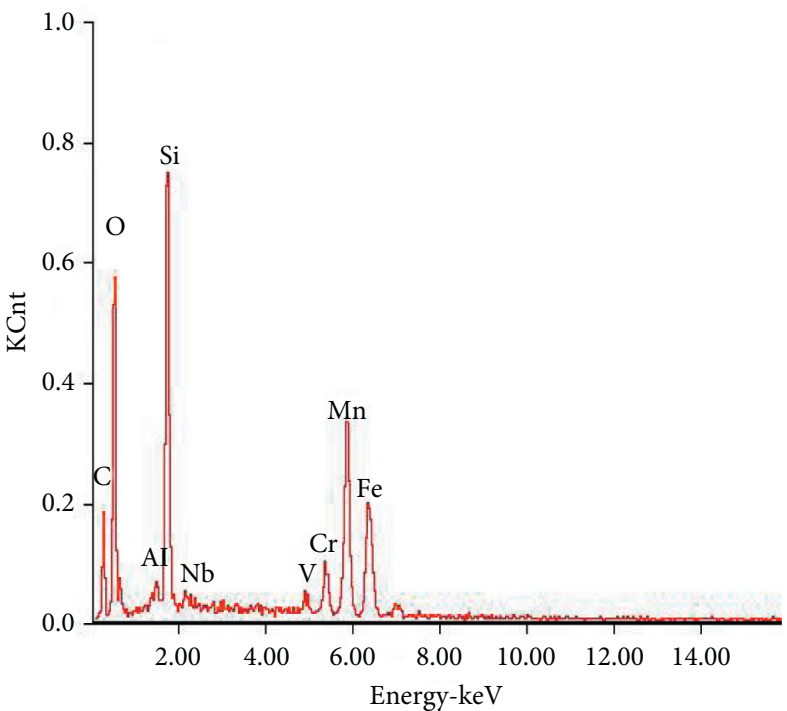

(d)

Figure 4: SEM image and EDS of the $2.25 \mathrm{Cr} 1 \mathrm{Mo} 0.25 \mathrm{~V}$ sample made by WAAM, where sample \#1 is in the as-cladded state. 


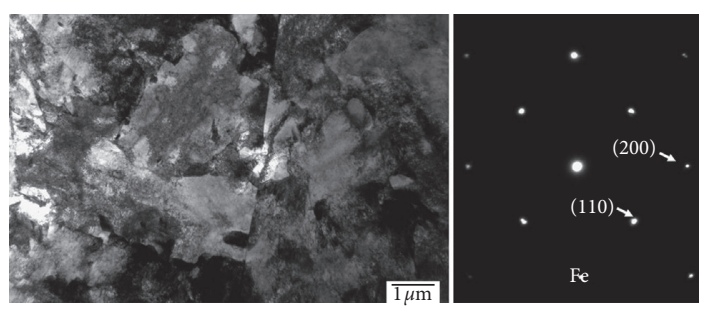

Figure 5: Microstructures of the as-cladded 2.25Cr1Mo0.25V sample made by WAAM.

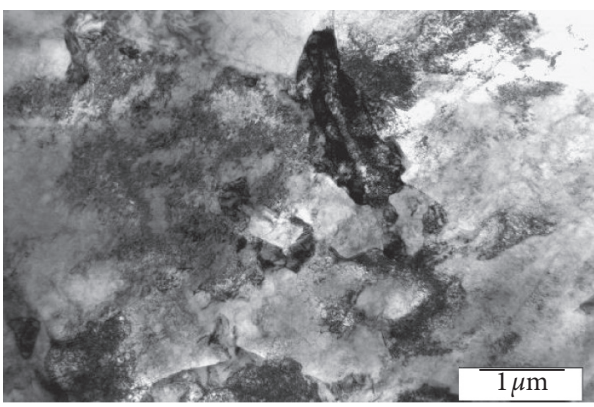

(a)

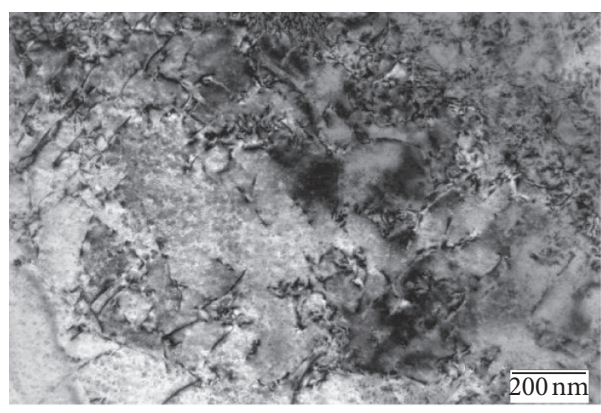

(c)

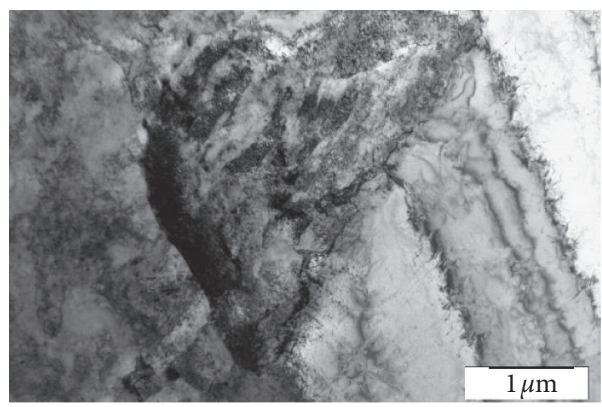

(b)

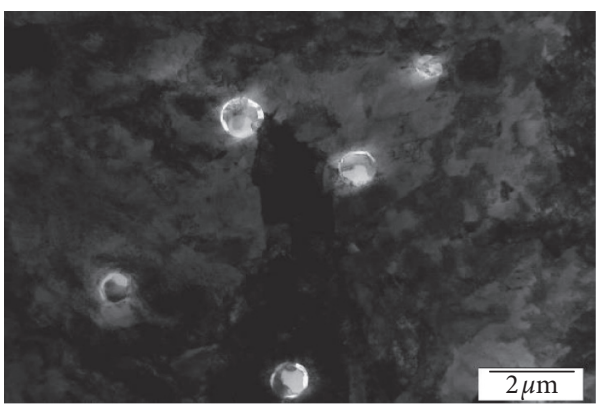

(d)

Figure 6: Microstructures of the as-cladded 2.25Cr1Mo0.25V sample made by WAAM: (a) bainite, (b) M-A constituent, (c) dislocations, and (d) inclusions.

image of the M-A constituent in the granular bainite that includes isolated islands, further proving the existence of the M-A constituent. Figure 6(c) shows that, in the highmagnification TEM image, a large number of dislocations are found in the crystal structure of the cladded $2.25 \mathrm{Cr} 1 \mathrm{Mo} 0.25 \mathrm{~V}$ sample made by WAAM because the 2.25Cr1Mo0.25V heat-resistant steel has high $\mathrm{Cr}$, Mo, and $\mathrm{V}$ alloying element contents. A high hardening capacity is prone to produce crystal defects, such as hardened structures and dislocations. Therefore, in engineering applications, $2.25 \mathrm{Cr} 1 \mathrm{Mo} 0.25 \mathrm{~V}$ heat-resistant steels need to undergo a postcladding heat treatment to improve their structure and performance. Figure 6(d) shows a highmagnification TEM image of an area with inclusions where it can be seen that the inclusions are mainly spherical, which is consistent with the results obtained by SEM in Figure 4. Figure 7 shows the composition of inclusions analysed by energy dispersive spectrometry and SAED on the transmission electron microscope. From the analysis results of Figure 7, it can be seen that the inclusions are composite structures. The main components of the light- coloured inclusions are oxides of silicon and manganese, and the SAED pattern shows that the inclusions are amorphous. The dark part of the inclusions is mainly composed of silicon oxide, and the analysis of the corresponding SAED pattern shows that $\mathrm{SiO}_{2}$ is the main component. Figure 8 shows a high-resolution image of lattice fringes in the inclusions and matrix. The analysis indicated that the high-resolution lattice fringes in Figure 8(a) correspond to the (021) crystal plane of $\mathrm{SiO}_{2}$ with $d 0.3186 \mathrm{~nm}$ (PDF\# 82-1599), which is consistent with the results of the energy dispersive spectroscopy analysis. In Figure 8(b), the high-resolution lattice fringes in the matrix indicate a d-spacing of approximately $0.2113 \mathrm{~nm}$, which corresponds to the (110) crystal plane of austenite Fe. Figure 9 shows the crystal structure and corresponding SAED of the $2.25 \mathrm{Cr} 1 \mathrm{Mo} 0.25 \mathrm{~V}$ sample made by WAAM after the heat treatment at $705^{\circ} \mathrm{C} \times 1 \mathrm{~h}$. From the diagram, it can be seen that the dislocations in the crystal structure after the heat treatment decrease, the crystal grains become smooth, and the structure is significantly improved compared with that of the as-cladded WAAM sample. 


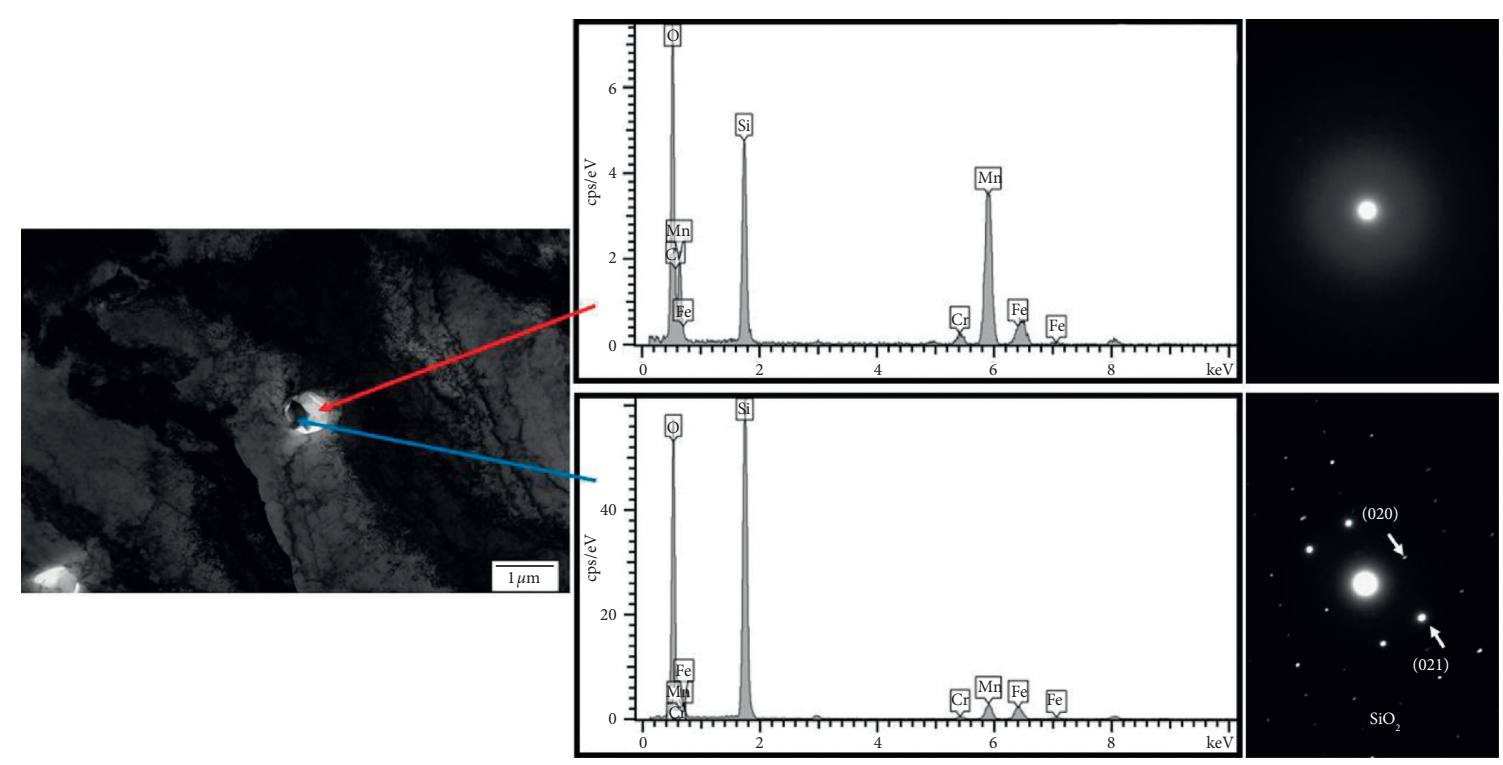

FIgURE 7: Morphology, EDS, and SAED of inclusions in the as-cladded 2.25Cr1Mo0.25V sample made by WAAM.

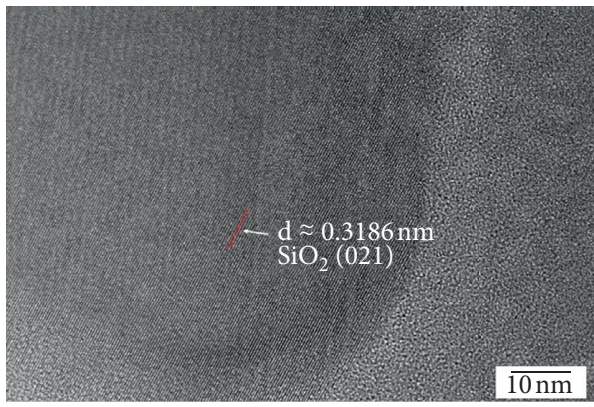

(a)

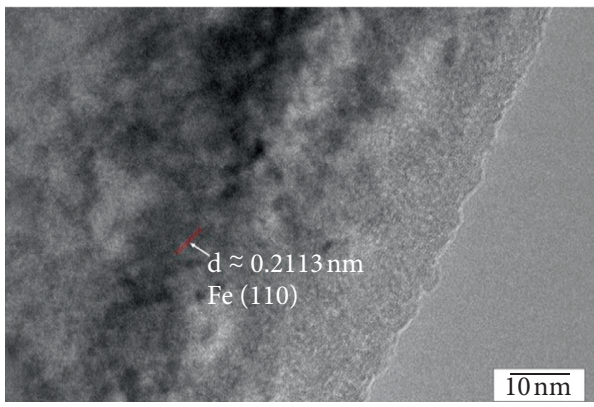

(b)

FIGURE 8: High-resolution transmission electron microscopy (HRTEM) image and corresponding SAED pattern of the as-cladded 2.25Cr1Mo0.25V sample made by WAAM: (a) inclusion and (b) matrix.

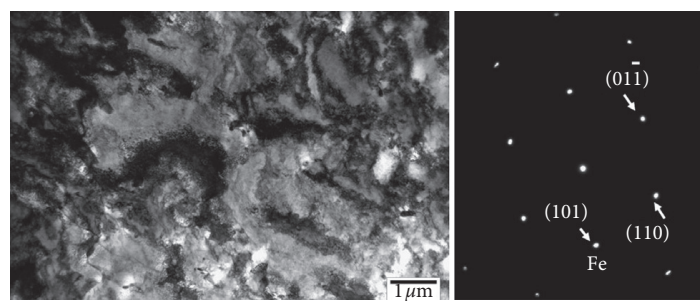

Figure 9: Microstructures of the 2.25Cr1Mo0.25V sample made by WAAM after the heat treatment.

According to the summary of the TEM images, the microstructure of the $2.25 \mathrm{Cr} 1 \mathrm{Mo} 0.25 \mathrm{~V}$ sample made by WAAM is mainly granular bainite at high magnifications. At high magnifications, dislocations and a small number of inclusions are found in the sample. The inclusions are mainly composed of silicon and manganese composite oxides, which is basically consistent with the results obtained by metallography and SEM. The microstructure of the sample obviously improves after the heat treatment.
3.3. Properties of the 2.25Cr1Mo0.25V Heat-Resistant Steel Sample Made by WAAM. Figure 10 shows the microhardness distribution of the $2.25 \mathrm{Cr} 1 \mathrm{Mo} 0.25 \mathrm{~V}$ heat-resistant steel sample made by WAAM. During the test, 10 points (with a $1 \mathrm{~mm}$ interval between the points) were measured equidistantly from the upper part $(2 \mathrm{~mm})$ to the lower part of the weld and from the left side $(2 \mathrm{~mm})$ to the right side. From the microhardness distribution diagram, it can be seen that the hardness distribution of the cladded samples (\#1) made of the 2.25Cr1Mo0.25V heat-resistant steel made by additive manufacturing ranges from 292 to $344 \mathrm{HV}_{0.5}$, and the distribution of the microhardness in the longitudinal and transverse cross sections of the samples is uniform. The average longitudinal and transverse microhardness of the samples in the ascladded state is $310 \mathrm{HV}_{0.5}$ and $324 \mathrm{HV}_{0.5}$, respectively. The difference in the average microhardness between the longitudinal and transverse sections is very small. The fluctuation of the microhardness is mainly caused by a change in the structure. From the cross-sectional morphology of the $2.25 \mathrm{Cr} 1 \mathrm{Mo} 0.25 \mathrm{~V}$ heat-resistant steel produced by WAAM in Figure 2, it can be 


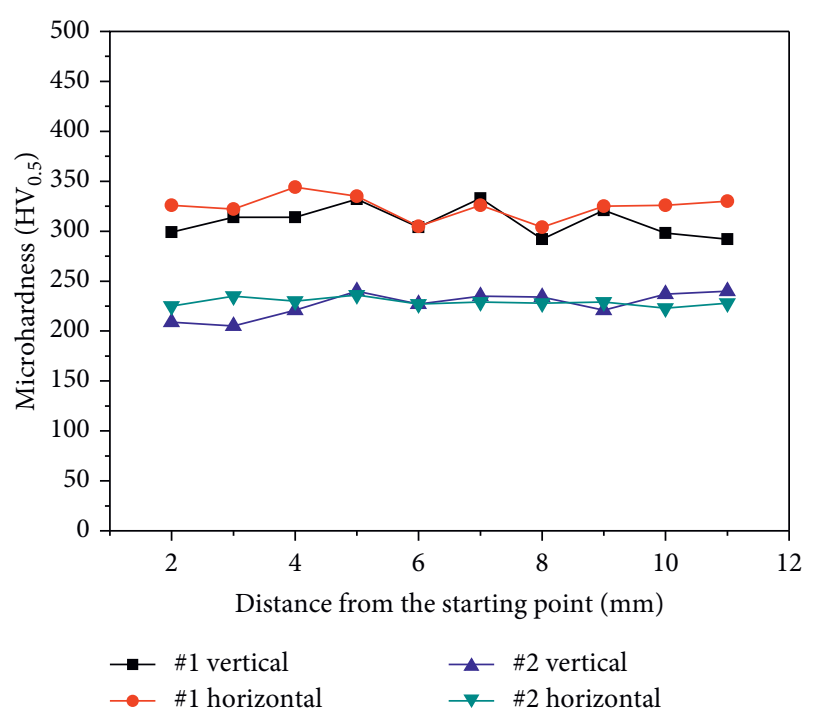

Figure 10: Microhardness distribution of the $2.25 \mathrm{Cr} 1 \mathrm{Mo} 0.25 \mathrm{~V}$ sample made by WAAM.

seen that the formed sample contains a multilayer and multipass cladding structure. The structure of the first layer of the cladded seam is affected by the thermal cycle of the second layer and the same layer of the cladded seam. Generally, there are primitive columnar crystal zones, remelting zones, and heat-affected zones. The microhardness varies in different regions due to the different microstructures (such as the grain size and presence of precipitates), so the cross-sectional hardness fluctuates. After the heat treatment, the hardness distribution ranges from 205 to $240 \mathrm{HV}_{0.5}$, and the average longitudinal and transverse microhardness of the section is $227 \mathrm{HV}_{0.5}$ and $229 \mathrm{HV}_{0.5}$, respectively. Upon comparing the cross-sectional microhardness of the $2.25 \mathrm{Cr} 1 \mathrm{Mo} 0.25 \mathrm{~V}$ heat-resistant steel produced by WAAM after cladding and heat treatment, it can be found that the average microhardness of the sample after the heat treatment decreases by approximately $90 \mathrm{HV}_{0.5}$, which is due to an improvement in the structure and stress release of the sample.

The test results of the mechanical properties of the $2.25 \mathrm{Cr} 1 \mathrm{Mo} 0.25 \mathrm{~V}$ heat-resistant steel produced by WAAM are shown in Figure 11. It can be seen from the test results that the mechanical properties of the specimens are excellent. The yield strength of the samples without a postcladding heat treatment is $743 \mathrm{MPa}$, the tensile strength is $951 \mathrm{MPa}$, the elongation is $10 \%$, and the Charpy impact value at $-20^{\circ} \mathrm{C}$ is $15 \mathrm{~J}$. After the postcladding heat treatment, the yield strength, tensile strength, elongation, and Charpy impact value at $-0^{\circ} \mathrm{C}$ of the samples are $611 \mathrm{MPa}, 704 \mathrm{MPa}, 14.5 \%$, and $70 \mathrm{~J}$, respectively.

\section{Conclusions}

WAAM was used to produce samples of a $2.25 \mathrm{Cr} 1 \mathrm{Mo} 0.25 \mathrm{~V}$ heat-resistant steel. The samples were of good quality. The microstructure consisted mainly of BG (granular bainite) and troostite that precipitated at the grain boundaries. The crystal structures of the $2.25 \mathrm{Cr} 1 \mathrm{Mo} 0.25 \mathrm{~V}$ heat-resistant steel samples produced by WAAM in the as-cladded condition had many defects, such as dislocations and M-A constituents. There was a

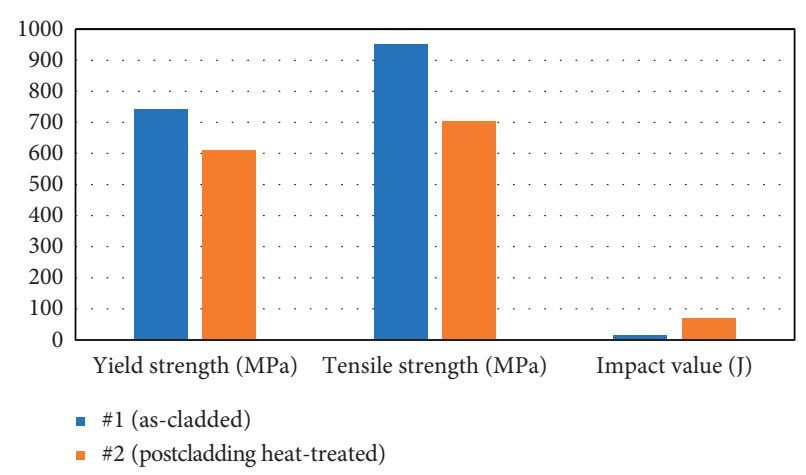

FIgURE 11: Mechanical properties of the 2.25Cr1Mo0.25V sample made by WAAM.

dramatic decrease in the dislocations in the $2.25 \mathrm{Cr} 1 \mathrm{Mo} 0.25 \mathrm{~V}$ heat-resistant steel samples produced by the WAAM condition of a postcladding heat treatment $\left(705^{\circ} \mathrm{C} \times 1 \mathrm{~h}\right)$, and their grains became smooth. A small number of inclusions were found in high-magnification SEM and TEM images. The inclusions were mainly composed of silicon and manganese oxides. The distribution of the microhardness in the longitudinal and transverse cross sections was uniform. The average longitudinal and transverse microhardness of the samples in the as-cladded state was $310 \mathrm{HV}_{0.5}$ and $324 \mathrm{HV}_{0.5}$, respectively. The average longitudinal and transverse microhardness of the samples after the heat treatment was $227 \mathrm{HV}_{0.5}$ and $229 \mathrm{HV}_{0.5}$, respectively. The yield strength of the samples without a postcladding heat treatment was $743 \mathrm{MPa}$, the tensile strength was $951 \mathrm{MPa}$, the elongation was $10 \%$, and the Charpy impact value at $-20^{\circ} \mathrm{C}$ was $15 \mathrm{~J}$. After the heat treatment, the yield strength, tensile strength, elongation, and Charpy impact value at $-20^{\circ} \mathrm{C}$ of the samples were $611 \mathrm{MPa}, 704 \mathrm{MPa}, 14.5 \%$, and $70 \mathrm{~J}$, respectively. This study is expected to provide theoretical and data support for additive manufacturing of heat-resistant steel parts.

\section{Data Availability}

Any reader or researcher who wishes to obtain the research data of this article can contact the author by e-mail.

\section{Conflicts of Interest}

The authors declare no conflicts of interest.

\section{Acknowledgments}

The authors wish to thank the University Synergy Innovation Program of Anhui Province (GXXT-2019-022), the Natural Science Foundation of Anhui Province (1908085QE174), and the Talent Program of Anhui Science and Technology University (RCYJ201905) for financial support.

\section{References}

[1] D. Zhang, D. Qiu, M. A. Gibson et al., "Additive manufacturing of ultrafine-grained high-strength titanium alloys," Nature, vol. 576, no. 7785, pp. 91-95, 2019. 
[2] J. P. Oliveira, T. G. Santos, and R. M. Miranda, "Revisiting fundamental welding concepts to improve additive manufacturing: from theory to practice," Progress in Materials Science, vol. 107, p. 100590, 2020.

[3] G. Bansal, D. Bandhu Singh, H. Singh Virk, and A. D.A. Bhandari, "Microstructural characterization, applications and process study of various additive manufacturing process: a review," Materials Today: Proceedings, 2020.

[4] J. Savolainen and M. Collan, "How additive manufacturing technology changes business models?-review of literature," Additive Manufacturing, vol. 32, Article ID 101070, 2020.

[5] M. J. Martín de Vidales, A. Nieto-Márquez, D. Morcuende et al., "3D printed floating photocatalysts for wastewater treatment," Catalysis Today, vol. 328, pp. 157-163, 2019.

[6] A. A. Giannopoulos, D. Mitsouras, S.-J. Yoo, P. P. Liu, Y. S. Chatzizisis, and F. J. Rybicki, "Applications of 3D printing in cardiovascular diseases," Nature Reviews Cardiology, vol. 13, no. 12, pp. 701-718, 2016.

[7] J. H. Martin, B. D. Yahata, J. M. Hundley, J. A. Mayer, T. A. Schaedler, and T. M. Pollock, "3D printing of highstrength aluminium alloys," Nature, vol. 549, no. 7672, pp. 365-369, 2017.

[8] R. Rahmani, M. Antonov, and L. Kollo, "Wear resistance of (diamond-Ni)-Ti6Al4V gradient materials prepared by combined selective laser melting and spark plasma sintering techniques," Advances in Tribology, vol. 2019, pp. 1-12, 2019.

[9] N. Prem, D. Sindersberger, and G. J. Monkman, "Mini-extruder for 3D magnetoactive polymer printing," Advances in Materials Science and Engineering, vol. 2019, Article ID 8715718, 8 pages, 2019.

[10] Z. Li, C. Liu, T. Xu et al., "Reducing arc heat input and obtaining equiaxed grains by hot-wire method during arc additive manufacturing titanium alloy," Materials Science and Engineering: A, vol. 742, pp. 287-294, 2019.

[11] A. Huang, "Electromagnetic vibration monitoring method for liquid transfer mode in wire feeding based laser additive manufacturing (WFLAM)," Journal of Mechanical Engineering, vol. 54, no. 2, pp. 34-40, 2018.

[12] Y.-y. Zhu, B. Chen, H.-b. Tang, X. Cheng, H.-m. Wang, and $\mathrm{J}$. Li, "Influence of heat treatments on microstructure and mechanical properties of laser additive manufacturing Ti-5Al2Sn-2Zr-4Mo-4Cr titanium alloy," Transactions of Nonferrous Metals Society of China, vol. 28, no. 1, pp. 36-46, 2018.

[13] B.-S. Lee, H.-J. Lee, K.-S. Lee, H. Giun Kim, and G.-H. K.C.-W. Lee, "Enhanced osseointegration of Ti6Al4V ELI screws built-up by electron beam additive manufacturing: an experimental study in rabbits," Applied Surface Science, vol. 508, Article ID 145160, 2019.

[14] K. Wang, Y. Liu, Z. Sun, J. Lin, Y. Lv, and B. Xu, "Microstructural evolution and mechanical properties of Inconel 718 superalloy thin wall fabricated by pulsed plasma arc additive manufacturing," Journal of Alloys and Compounds, vol. 819, Article ID 152936, 2020.

[15] T. Lu, C. Liu, Z. Li et al., "Hot-wire arc additive manufacturing Ti-6.5Al-2Zr-1Mo-1V titanium alloy: pore characterization, microstructural evolution, and mechanical properties," Journal of Alloys and Compounds, vol. 817, Article ID 153334, 2020.

[16] X. Xu, S. Ganguly, J. Ding, S. Guo, S. Williams, and F. Martina, "Microstructural evolution and mechanical properties of maraging steel produced by wire + arc additive manufacture process," Materials Characterization, vol. 143, pp. 152-162, 2018.
[17] X. Chen, J. Li, X. Cheng, B. He, H. Wang, and Z. Huang, "Microstructure and mechanical properties of the austenitic stainless steel 316L fabricated by gas metal arc additive manufacturing," Materials Science and Engineering: A, vol. 703, pp. 567-577, 2017.

[18] F. Wang, S. Williams, P. Colegrove, and A. A. Antonysamy, "Microstructure and mechanical properties of wire and arc additive manufactured Ti-6Al-4V," Metallurgical and Materials Transactions A, vol. 44, no. 2, pp. 968-977, 2012.

[19] M. J. Bermingham, L. Nicastro, D. Kent, Y. Chen, and M. S. Dargusch, "Optimising the mechanical properties of Ti$6 \mathrm{Al}-4 \mathrm{~V}$ components produced by wire + arc additive manufacturing with post-process heat treatments," Journal of Alloys and Compounds, vol. 753, pp. 247-255, 2018.

[20] A. Vahedi Nemani, M. Ghaffari, and A. Nasiri, "Comparison of microstructural characteristics and mechanical properties of shipbuilding steel plates fabricated by conventional rolling versus wire arc additive manufacturing," Additive Manufacturing, vol. 32, p. 101086, 2020.

[21] A. Lopez, R. Bacelar, I. Pires, T. G. Santos, J. P. Sousa, and L. Quintino, "Non-destructive testing application of radiography and ultrasound for wire and arc additive manufacturing," Additive Manufacturing, vol. 21, pp. 298306, 2018.

[22] X. Xu, J. Ding, S. Ganguly, C. Diao, and S. Williams, "Oxide accumulation effects on wire + arc layer-by-layer additive manufacture process," Journal of Materials Processing Technology, vol. 252, pp. 739-750, 2018.

[23] F. Hejripour, D. T. Valentine, and D. K. Aidun, "Study of mass transport in cold wire deposition for Wire Arc Additive Manufacturing," International Journal of Heat and Mass Transfer, vol. 125, pp. 471-484, 2018.

[24] Y. Li, S. Yu, Y. Chen, R. Yu, and Y. Shi, "Wire and arc additive manufacturing of aluminum alloy lattice structure," Journal of Manufacturing Processes, vol. 50, pp. 510-519, 2020.

[25] D. Wen, P. Long, J. Li, L. Huang, and Z. Zheng, "Effects of linear heat input on microstructure and corrosion behavior of an austenitic stainless steel processed by wire arc additive manufacturing," Vacuum, vol. 173, p. 109131, 2020.

[26] Y. Ali, P. Henckell, J. Hildebrand, J. Reimann, J. P. Bergmann, and S. Barnikol-Oettler, "Wire arc additive manufacturing of hot work tool steel with CMT process," Journal of Materials Processing Technology, vol. 269, pp. 109-116, 2019.

[27] D. R. Manca, A. Y. Churyumov, A. V. Pozdniakov et al., "Microstructure and properties of novel heat resistant Al-Ce$\mathrm{Cu}$ alloy for additive manufacturing," Metals and Materials International, vol. 25, no. 3, pp. 633-640, 2019.

[28] M. Wang, Y. Huang, and K. L.W. Tseng, "Metal powders with fine microstructure of high heat-resistant steel for additive manufacturing produced by C-D nozzle," in Proceedings of IEEE International Conference on Industrial Technology, pp. 2163-2168, Taipei, Taiwan, May 2016.

[29] J. Huo and X. D.L. Zhu, "Evolution of microstructure for $2.25 \mathrm{Cr} 1 \mathrm{Mo} 0.25 \mathrm{~V}$ steel under condition of elevated temperature creep," Heavy Casting and Forging, vol. 3, pp. 33-37, 2019.

[30] L. Song, R. Sun, and W. G.L. Duan, "Impact properties and microstructure of welded joints of $2.25 \mathrm{Cr}-1 \mathrm{Mo}-0.25 \mathrm{~V}$," Transactions of the China Welding Institution, vol. 34, no. 12, pp. 105-109, 2013.

[31] X. Ma, C. Hu, and H. Q.Y. Jiang, "Ef fect of heat treatment process on critical transformation temperature of 2 .25Cr1Mo0 .25V steel," Journal of Petrochemical Universities, vol. 24, no. 3, pp. 70-81, 2011. 